\title{
Combining Varenicline (Chantix) with Naltrexone Decreases Alcohol Drinking More Effectively Than Does Either Drug Alone in a Rodent Model of Alcoholism
}

\author{
Janice C. Froehlich, Stephen M. Fischer, Julian E. Dilley, Emily R. Nicholson, Teal N. Smith, \\ Nick J. Filosa, and Logan C. Rademacher
}

\begin{abstract}
Background: This study examined whether varenicline (VAR), or naltrexone (NTX), alone or in combination, reduces alcohol drinking in alcohol-preferring $(\mathrm{P})$ rats with a genetic predisposition toward high voluntary alcohol intake.

Methods: Alcohol-experienced $\mathrm{P}$ rats that had been drinking alcohol $(15 \% \mathrm{v} / \mathrm{v})$ for $2 \mathrm{~h} / \mathrm{d}$ for 4 weeks were fed either vehicle (VEH), VAR alone $(0.5,1.0$, or $2.0 \mathrm{mg} / \mathrm{kg}$ body weight [BW]), NTX alone $(10.0,15.0$, or $20.0 \mathrm{mg} / \mathrm{kg} \mathrm{BW})$, or VAR + NTX in 1 of 4 dose combinations $(0.5 \mathrm{VAR}+10.0$ NTX, 0.5 VAR + 15.0 NTX, 1.0 VAR + 10.0 NTX, or 1.0 VAR + 15.0 NTX) at 1 hour prior to alcohol access for 10 consecutive days, and the effects on alcohol intake were assessed.

Results: When administered alone, VAR in doses of 0.5 or $1.0 \mathrm{mg} / \mathrm{kg} \mathrm{BW}$ did not alter alcohol intake but a dose of $2.0 \mathrm{mg} / \mathrm{kg}$ BW decreased alcohol intake. This effect disappeared when drug treatment was terminated. NTX in doses of 10.0 and $15.0 \mathrm{mg} / \mathrm{kg} \mathrm{BW}$ did not alter alcohol intake but a dose of $20.0 \mathrm{mg} / \mathrm{kg} \mathrm{BW}$ decreased alcohol intake. Combining low doses of VAR and NTX into a single medication reduced alcohol intake as well as did high doses of each drug alone. Reduced alcohol intake occurred immediately after onset of treatment with the combined medication and continued throughout prolonged treatment.

Conclusions: Low doses of VAR and NTX, when combined in a single medication, reduce alcohol intake in a rodent model of alcoholism. This approach has the advantage of reducing potential side effects associated with each drug. Lowering the dose of NTX and VAR in a combined treatment approach that maintains efficacy while reducing the incidence of negative side effects may increase patient compliance and improve clinical outcomes for alcoholics and heavy drinkers who want to reduce their alcohol intake.
\end{abstract}

Key Words: Alcohol Drinking, Alcohol Treatment, Selectively Bred Rats, Naltrexone, Varenicline.

A LCOHOLISM IS THE most prevalent and widespread of all addictive diseases, and development of effective treatments for alcohol abuse and alcoholism is a worldwide priority. Only 3 drugs have been approved by the Food and Drug Administration (FDA) for the treatment of alcohol dependence: disulfiram (antabuse), acamprosate, and naltrexone (NTX; Trexan or Revia) (Anton et al., 2006). NTX is more effective than is acamprosate (Maisel et al., 2013) and exhibits better compliance than does disulfiram (Anton et al., 2006; Fuller et al., 1986), but it remains underutilized because its efficacy is modest (Froehlich et al., 2003; O'Malley and Froehlich, 2003), it is not effective for all alcoholics (Kranzler et al., 2000; Krystal et al., 2001), and, when it is

From the Indiana University School of Medicine (JCF, JED, ERN, $T N S, N J F, L C R)$, Indianapolis, Indiana; and Department of Medicine (SMF), University of Michigan, Ann Arbor, Michigan.

Received for publication March 21, 2016; accepted June 8, 2016.

Reprint requests: Janice C. Froehlich, PhD, Indiana University School of Medicine, 975 West Walnut Street IB 424, Indianapolis, IN 462025124; Tel.: 317-274-1347; Fax: 317-274-2695; E-mail: jcfroehl@iu.edu Copyright $(2016$ by the Research Society on Alcoholism.

DOI: 10.1111/acer.13157 effective, many alcoholics fail to maintain initial treatment gains and relapse to heavy drinking (Anton et al., 2006; Krishnan-Sarin et al., 2007; Krystal et al., 2001). Clearly, additional medications for the treatment of alcohol abuse and alcoholism are needed.

Opioid antagonists were first shown to decrease alcohol drinking in rats selectively bred for high voluntary alcohol intake (Froehlich and Li, 1991; Froehlich et al., 1990, 1991). This preclinical work led to studies on the effects of NTX, a nonspecific opioid receptor antagonist, on alcohol drinking in humans. NTX decreases alcohol intake and reduces alcohol relapse rates in alcoholics and heavy drinkers (O'Malley et al., 1992; Ray et al., 2010; Volpicelli et al., 1992). It reduces the reinforcing effects of alcohol by antagonizing beta-endorphin stimulated dopamine (DA) release in the brain during alcohol exposure (Di Chiara and Imperato, 1988; Imperato and Di Chiara, 1986; Koob, 1992). Subjects receiving NTX reported that the "high" they experienced from alcohol was less than they had previously experienced in the absence of NTX and was less than they had expected to experience when they drank alcohol (Volpicelli et al., 1995). The alcoholics who "slipped" and drank alcohol while taking NTX 
consumed less alcohol than did those taking placebo, were able to stop drinking after a few drinks, and were less likely to drink to intoxication.

Varenicline (VAR), an $\alpha 4 \beta 2$ nicotinic acetylcholinergic receptor partial agonist, marketed as CHANTIX $^{\circledR}$ in the United States, and as CHAMPIX ${ }^{\circledR}$ in Europe and elsewhere, was FDA approved for smoking cessation in 2006. Recent preclinical studies suggest that VAR also reduces alcohol, as well as nicotine, intake in rats and humans by blocking both alcohol and nicotine-induced excitation of the DA system (Chatterjee et al., 2011; Fucito et al., 2011; McKee et al., 2009; Steensland et al., 2007). In a preliminary study, we found that VAR decreases alcohol intake in a rodent model of alcoholism; that is, in rats selectively bred for alcohol preference and high voluntary alcohol drinking ("P" rats). This agrees well with other reports that VAR reduces operant self-administration of alcohol in rats (Bito-Onon et al., 2011) and reduces alcohol drinking in Wistar rats induced to drink alcohol via the sucrose fade procedure (Steensland et al., 2007). In humans, a preliminary study in heavy alcohol drinking smokers reported that VAR $(2.0 \mathrm{mg} / \mathrm{d})$, compared to placebo, decreased alcohol craving, the number of drinks consumed, and the subjective reinforcing effects of alcohol (e.g., "high" or "intoxication"), and increased the likelihood of abstaining from drinking (McKee et al., 2009). The subjects were not deprived of nicotine in this study which indicates that VAR decreased alcohol drinking independent of its effects on nicotine. O'Malley and colleagues (Fucito et al., 2011) gave 30 heavy drinking smokers VAR $(2.0 \mathrm{mg} /$ d) or placebo for 5 or 8 weeks and found that VAR was well tolerated, and compared to placebo, VAR decreased alcohol craving as well as the number of heavy alcohol drinking days.

Given that both VAR and NTX, when administered alone, can decrease alcohol drinking in rats and humans, we hypothesized that VAR and NTX, when combined, would act more effectively to decrease alcohol drinking than would either drug alone. The fact that VAR and NTX, when given alone, reduce alcohol drinking in both $P$ rats and in heavy drinkers lends predictive validity to the use of $\mathrm{P}$ rats as a rodent model of alcoholism that is appropriate for characterizing the effects of combining VAR + NTX on alcohol drinking (Froehlich et al., 2003; O'Malley and Froehlich, 2003). This study addressed the following questions in P rats: (i) Does VAR + NTX in combination reduce alcohol intake more effectively than dose either drug alone? (ii) Does a reduction in drinking occur quickly after onset of treatment with the combined drug? and (iii) Is the reduction sustained throughout prolonged administration?

\section{MATERIALS AND METHODS}

\section{Subjects}

Fifty-nine alcohol-naïve male $\mathrm{P}$ rats from the 77 th generation of selective breeding for alcohol preference ( $\mathrm{P}$ line) served as subjects in all studies except when blood alcohol concentration (BAC) was examined. In that study, a subset of 15 of the 59 rats served as subjects. At the onset of the study, all rats were between 148 and 158 days of age. The rats were individually housed in stainless steel hanging cages located in an isolated vivarium with controlled temperature $\left(21 \pm 1^{\circ} \mathrm{C}\right)$ and a 12-hour light/dark cycle with lights off at 0900 hours. Standard rodent chow (Laboratory Rodent Diet \#7001; Harlan Teklad, Madison, WI) and water were available ad libitum. All experimental procedures were approved by the Indiana University Institutional Animal Care and use Committee and conducted in strict compliance with the NIH Guide for the Care and Use of Laboratory Animals.

\section{Alcohol Solution}

A $15 \%(v / v)$ alcohol solution was prepared by diluting $95 \%$ alcohol (ethanol) with distilled and deionized water. The alcohol solution and water were presented in separate calibrated glass drinking tubes, and daily intakes were recorded to the nearest milliliter. Alcohol intake in milliliters was converted to $\mathrm{g}$ alcohol $/ \mathrm{kg}$ body weight (BW) prior to data analysis.

\section{Drug Preparation and Oral Delivery}

Varenicline tartrate (VAR) (Pfizer Int., Groton, CT) and naltrexone hydrochloride (NTX) (Sigma-Aldrich, St. Louis, MO) were dissolved in deionized and distilled water using sonication at $55^{\circ} \mathrm{C}$. The stock solution containing drug was added to a sweetened gelatin solution comprised of berry flavored Jell-O and gelatin in distilled and deionized water. VAR and NTX, expressed as free base masses, were added to the gelatin solution to provide the following doses: $0.5,1.0$, and $2.0 \mathrm{mg}$ of VAR/3.0 ml solution/kg BW; 10.0, 15.0, and $20.0 \mathrm{mg}$ of NTX/ $3.0 \mathrm{ml}$ solution $/ \mathrm{kg} \mathrm{BW}$; and 0.5 or $1.0 \mathrm{mg} \mathrm{VAR}+15.0 \mathrm{mg}$ $\mathrm{NTX} / 3.0 \mathrm{ml}$ solution $/ \mathrm{kg} \quad \mathrm{BW}$, and 0.5 or $1.0 \mathrm{mg}$ $\mathrm{VAR}+10.0 \mathrm{mg} \mathrm{NTX} / 3.0 \mathrm{ml}$ solution $/ \mathrm{kg} \mathrm{BW}$. While still hot, the gelatin solution containing the $\operatorname{drug}(\mathrm{s})$ was aliquoted into star-shaped molds, 1 per rat, with the volume of each aliquot determined by the final concentration of the gelatin (mg drug/ $\mathrm{ml}$ of gelatin solution) and the BW of the animal to produce individual drug dosing, 1 dose per day per rat, as previously described (Froehlich et al., 2013a). The flavored, star-shaped pieces of gelatin (approximately $1.8 \mathrm{~g}$ ), containing VAR and NTX, alone or in combination, were fed to the rats once each day by inserting them through a hole in the front of the cage. The rats consistently ate the gelatin within 1 minute. Cages were checked to confirm that no pieces of gelatin were dropped. On the rare occasion that rats dropped the gelatin star, the star was refed to the rat. Gelatin was fed each day at 1 hour prior to onset of the daily 2-hour alcohol access period, except in 1 study where the time between oral drug delivery and onset of VAR treatment was the dependent variable. All rats were fed vehicle (VEH) gelatin (no drug) once a day for 5 consecutive days prior to the initiation of drug treatment in order to acquaint them with the oral drug administration procedure. We have previously found that consumption of the flavored gelatin with no drug $(\mathrm{VEH})$ at 1 hour prior to daily 2hour access to alcohol does not alter alcohol intake (data not shown). Specifically, the average daily 2-hour alcohol intake during the 5 days prior to consumption of $\mathrm{VEH}$ gelatin was $1.8 \mathrm{~g} / \mathrm{kg} \mathrm{BW}(N=64$ adult male $\mathrm{P}$ rats $)$ and average daily 2hour alcohol intake in the same rats during 5 days of consumption of $\mathrm{VEH}$ gelatin was $1.7 \mathrm{~g} / \mathrm{kg} \mathrm{BW}$. We routinely use this oral drug delivery approach successfully for the prolonged administration of drugs such as prazosin, NTX, or VAR (Froehlich et al., 2013a,b). It is appropriate for any drug that is water soluble and orally active. 


\section{Alcohol Drinking Induction}

All rats were provided with access to food, water, and a $15 \%$ $(\mathrm{v} / \mathrm{v})$ alcohol solution, and the alcohol solution was introduced using a "step-down" procedure as previously described (Froehlich et al., 2013a,b) to maximize alcohol intake during a restricted 2-hour daily alcohol access period. Alcohol was first available for 8 hours a day for 5 days, and then access was reduced to 4 hours a day for 10 days and finally to 2 hours a day for 28 days. Throughout each study rats were maintained with free access to food and water and scheduled access to the $15 \%(\mathrm{v} / \mathrm{v})$ alcohol solution for 2 hours a day (from 1000 hours, onset of dark, to 1200 hours). Alcohol and water intake were recorded daily, and BW was recorded once a week. This step-down procedure produces stable drinking at approximately $2.0 \mathrm{~g} / \mathrm{kg} \mathrm{BW} / 2 \mathrm{~h}$ in $\mathrm{P}$ rats (Rasmussen et al., 2009). All rats had served as subjects in a prior study with VAR, 11 weeks earlier, and were maintained with ad lib food and water and 2-hour daily access to alcohol $(15 \% \mathrm{v} / \mathrm{v})$ for 4 additional weeks prior to introducing the alcohol drinking induction protocol.

\section{Assigning Rats to Groups}

Rats were ranked in descending order of average daily 2-hour alcohol intake for 5 consecutive days prior to onset of drug treatment and were assigned to dose groups in a manner that ensured that alcohol intake did not differ between groups prior to initiation of drug treatment, as previously described (Froehlich et al., 2013a,b).

\section{Experimental Design}

$V A R$ on Alcohol Intake. Rats were fed VAR $(0.5,1.0,2.0 \mathrm{mg} /$ $\mathrm{kg} \mathrm{BW})$ or $\mathrm{VEH}$ in gelatin 1 hour prior to onset of each daily 2hour alcohol access period for $5 \mathrm{~d} /$ wk for 2 weeks. This was followed by continued ad libitum access to food, water, and continued daily 2-hour access to alcohol without drug for 2 weeks (postdrug days). To assess whether a longer lead time between drug administration and alcohol access would increase the efficacy of VAR, a subset of 49 male $P$ rats were randomly selected and were fed VEH gelatin stars at 2 hours prior to onset of daily 2-hour alcohol access for 5 days and daily alcohol intake was assessed. They were then assigned to VAR drug dose groups as previously described and were fed VAR $(0.5,1.0$, or $2.0 \mathrm{mg} / \mathrm{kg}$ $\mathrm{BW}$ ) or VEH, once daily, at 2 hours prior to onset of the daily 2-hour alcohol access period for 5 consecutive days. Doses of VAR above $2.0 \mathrm{mg} / \mathrm{kg}$ were not used because higher doses of VAR are no longer specific for the alpha-2-beta-4 and/or alpha-7 nicotine acetylcholine receptors (Rollema et al., 2007; conversation with Hans Rollema), and doses above $3.0 \mathrm{mg} / \mathrm{kg}$ decrease food intake in rats, presumably via induction of nausea (Faessel et al., 2006; O’Connor et al., 2009).

NTX on Alcohol Intake. Rats were fed NTX (10.0, 15.0, or $20.0 \mathrm{mg} / \mathrm{kg} \mathrm{BW}$ ) or $\mathrm{VEH}$ in gelatin stars at 1 hour prior to onset of each daily 2-hour alcohol access period for 5 days a week for 2 weeks.

$V A R+N T X$ Combined. Another group of alcohol-naïve adult male $\mathrm{P}$ rats $(N=59)$ was induced to drink alcohol as described above. They were then maintained with ad lib food and water and 2-hour daily access to alcohol $(15 \% \mathrm{v} / \mathrm{v})$ for 4 weeks prior to onset of drug treatment. All rats were counterbalanced and assigned to drug dose groups as described above. Rats were fed VEH or VAR + NTX $(0.5 \mathrm{VAR}+10.0 \mathrm{NTX}$ or $0.5 \mathrm{VAR}+15.0 \mathrm{NTX}$ or 1.0 VAR + 10.0 NTX or 1.0 VAR + 15.0 NTX) in gelatin stars at 1 hour prior to onset of each daily 2-hour alcohol access period for
5 days a week for 3 weeks. The VAR and NTX doses that were chosen to be combined were those that were ineffective in decreasing alcohol intake when given alone.

$V A R+N T X$ on BAC. After completion of the VAR + NTX study, $15 \mathrm{P}$ rats were randomly selected from that study and were maintained with ad libitum access to food and water and limited access to alcohol $(15 \% \mathrm{v} / \mathrm{v})$ for 2 hours a day for 5 weeks. The rats were counterbalanced based on alcohol intake and assigned to the VEH or the drug treatment group as described above. The rats were fed gelatin gummy stars containing no drug $(\mathrm{VEH})$ or containing $1.0 \mathrm{mg}$ VAR $+10.0 \mathrm{mg} \mathrm{NTX} / \mathrm{kg} \mathrm{BW}$ at 1 hour prior to onset of the daily 2-hour alcohol access period for 5 days prior to an intragastric (IG) infusion of alcohol and determination of BAC. It is known that NTX alone does not alter BAC (Linesman and Le, 1997), but the effect of VAR on BAC is not known. We chose the highest dose of VAR that had been used in combination with NTX so that if the drug combination did alter BAC, it would be seen at this dose. On the night before IG infusion and BAC determination, food was removed from all rats' cages and each rat was given $7 \mathrm{~g}$ of food which served to minimize and equate the amount of food present in the stomach at time of IG infusion of alcohol. This serves to reduce individual differences in the rate of alcohol absorption from the stomach and reduces variability in BAC following an alcohol infusion. On the day of BAC determination, rats were given IG alcohol in a dose of $2.0 \mathrm{~g}$ alcohol $/ 10.1 \mathrm{ml}$ of a $25 \% \mathrm{v} / \mathrm{v}$ alcohol solution $/ \mathrm{kg}$ BW. This dose is similar to the amount of alcohol that $\mathrm{P}$ rats consume in a daily 2-hour alcohol access period (Froehlich et al., 2013a,b, 2015; Rasmussen et al., 2009). This dose produces physiologically relevant BACs (Murphy et al., 1986) that are almost twice the human legal limit for intoxication ( $\mathrm{Li}$ et al., 1998), but are below the threshold that produces damage to the gastric mucosa (Gillespie and Lucas, 1961) or that induces smooth muscle paralysis (Bernard et al., 1964). The volume infused is also well below the gastric capacity of an adult rat (Bull and Pitts, 1971). Tail blood was collected at 15, 30, 60, 90, 120, 180, and 240 minutes after onset of the IG alcohol infusion. A razor blade was used to cut the tip $(<1 \mathrm{~mm})$ of the tail, and $0.075 \mathrm{ml}$ of blood was collected into a heparinized capillary tube, dispensed into an ice-cold $0.5-\mathrm{ml}$ microcentrifuge tube, sealed, and centrifuged at $4^{\circ} \mathrm{C}$. Spontaneous bleeding stopped immediately after sample collection, and subsequent samples were collected by removing the coagulate from the tip of the tail. Plasma was extracted and frozen at $-20^{\circ} \mathrm{C}$ until assayed for alcohol content by gas chromatography using a Hewlett-Packard 6890 series gas chromatography with auto injection (Palo Alto, CA). The column used was a HP-Innowax (cross-linked polyethylene glycol, $30 \mathrm{~m} \times 0.25 \mathrm{~mm} \times 0.25 \mu \mathrm{m}$ ), and the internal standard was 1-propanol.

\section{Data Analysis}

Alcohol intake was analyzed using 2-way repeated-measures (RM) analysis of variance (ANOVA) (treatment $\times$ day, RM on day) followed, when justified, by pairwise multiple comparisons using either Fisher's least significant difference (LSD) test when the interaction term was significant or Dunnett's multiple comparisons against a single mean when the interaction term was not significant. Significance was accepted at $p<0.05$, and data are represented as means $\pm \mathrm{SE}$. BACs were analyzed using a 2-way RM ANOVA (dose $\times$ time, with RM on time). Data were analyzed for extreme scores using the Dixon extreme score test and a conservative cutoff of $p<0.01$. Only 3 scores (in experiment 2) were excluded from the data set prior to statistical analyses. Extreme scores were replaced with the mean alcohol intake on the day prior to, and the day following the day when the extreme score was recorded. Consumption of less than three-quarters of the gelatin star resulted in exclusion of the drinking score for that 
rat on that day which occurred 4 times in the NTX alone study and 1 time in the VAR 1-hour lead time study.

\section{RESULTS}

\section{Alcohol Drinking Induction}

During the first phase of alcohol drinking induction, $\mathrm{P}$ rats consumed roughly $4.0 \mathrm{~g}$ alcohol $/ \mathrm{kg}$ BW per day during an 8hour free choice between the alcohol solution $(15 \% \mathrm{v} / \mathrm{v})$ and water. This corresponds to a $70-\mathrm{kg}$ person (154 pounds) drinking 5 to 6 standard drinks. A standard drink contains approximately $14 \mathrm{~g}$ of alcohol (NIAAA, 2008). The alcohol elimination rate (AER) of rats is $0.44 \mathrm{~g} / \mathrm{kg} \mathrm{BW} / \mathrm{h}$ (Parselak et al., 2004), which is approximately 4 times the AER of humans $(0.11 \mathrm{~g} / \mathrm{kg} \mathrm{BW} / \mathrm{h})$ (Forsander and Sinclair, 1992). During drinking induction, when the daily alcohol access period was reduced to 2 hours a day, the P rats consumed an average of approximately $2.0 \mathrm{~g}$ alcohol $/ \mathrm{kg} \mathrm{BW}$, which is equivalent to a human drinking 3 drinks in 2 hours (Fig. 1).

\section{Effect of VAR Alone on Alcohol Intake (1-Hour Lead Time)}

Alcohol intake during the 2 weeks of VAR treatment (5 d/wk) was analyzed with a 2-way RM ANOVA (dose $\times$ day, RM on day). There was a significant effect of dose, $F(3,55)=9.284, p<0.001$, a significant effect of day, $F(9,495)=10.23, p<0.001$, and no significant interaction $(p=0.78)$ (Fig. $2 A)$. Dunnett's multiple comparisons against a single mean revealed that only the $2.0 \mathrm{mg} / \mathrm{kg} \mathrm{BW}$ dose of VAR significantly reduced alcohol intake $(p<0.001)$ when compared to VEH (Fig. 2B). To further assess the effect of day, 1-way ANOVAs were conducted, one for each of the 10 days of treatment, for VAR in a dose of $2.0 \mathrm{mg} / \mathrm{kg} \mathrm{BW}$. VAR reduced alcohol intake on all 10 days of drug treatment ( $p<0.05, p<0.01$, or $p<0.001$ depending on the day) when compared to VEH.

With regard to alcohol intake following termination of drug treatment, there was a strong trend toward a significant effect of dose $(p=0.06)$, a significant effect of day, $F(4,220)=$ 11.22, $p<0.001$, and no interaction ( $p=0.55$; Fig. $2 A)$. Visual inspection of the data revealed that the trend for dose was due to the $2.0 \mathrm{mg} / \mathrm{kg} \mathrm{BW}$ dose of VAR which was further analyzed with separate 1-way analyses, one for each postdrug day, comparing 2.0 VAR and VEH. There was a very strong trend toward a reduction of alcohol intake on day 1 following termination of drug treatment $(p=0.053)$, but no significant effect was seen on any days thereafter.

\section{Effect of VAR Alone on Alcohol Intake (2-Hour Lead Time)}

The 2-way RM ANOVA (dose $\times$ day, RM on day) on days 1 to 5 of drug treatment revealed a significant effect of dose, $F(3,44)=2.91, p<0.05$, no significant effect of day $(p=0.12)$, and no significant interaction $(p=0.77)$. Dunnett's multiple comparisons against a single mean revealed that no dose significantly decreased or increased alcohol consumption when compared to VEH (Fig. 3).

With regard to alcohol intake following termination of treatment, there was no effect of dose $(p=0.95)$, a significant effect of day, $F(4,175)=3.17, p<0.05$, and no interaction $(p=0.52)$.

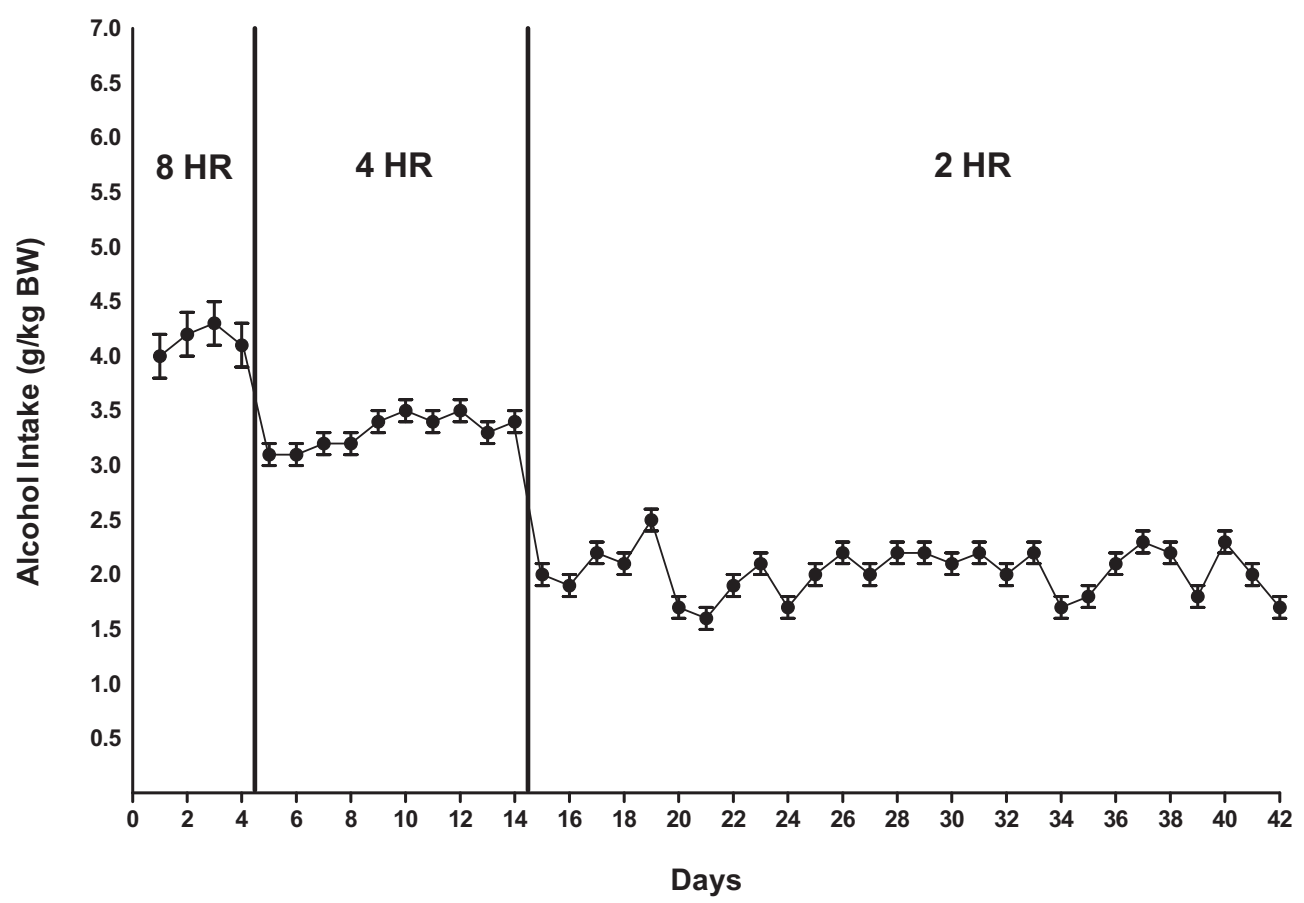

Fig. 1. Alcohol intake in male $P$ rats given scheduled access to alcohol (15\% v/v) for 8 hours a day for 4 days, followed by 4 hours a day for 10 days, and 2 hours a day for 28 days prior to the initiation of drug treatment. Each point represents the mean \pm SE. 

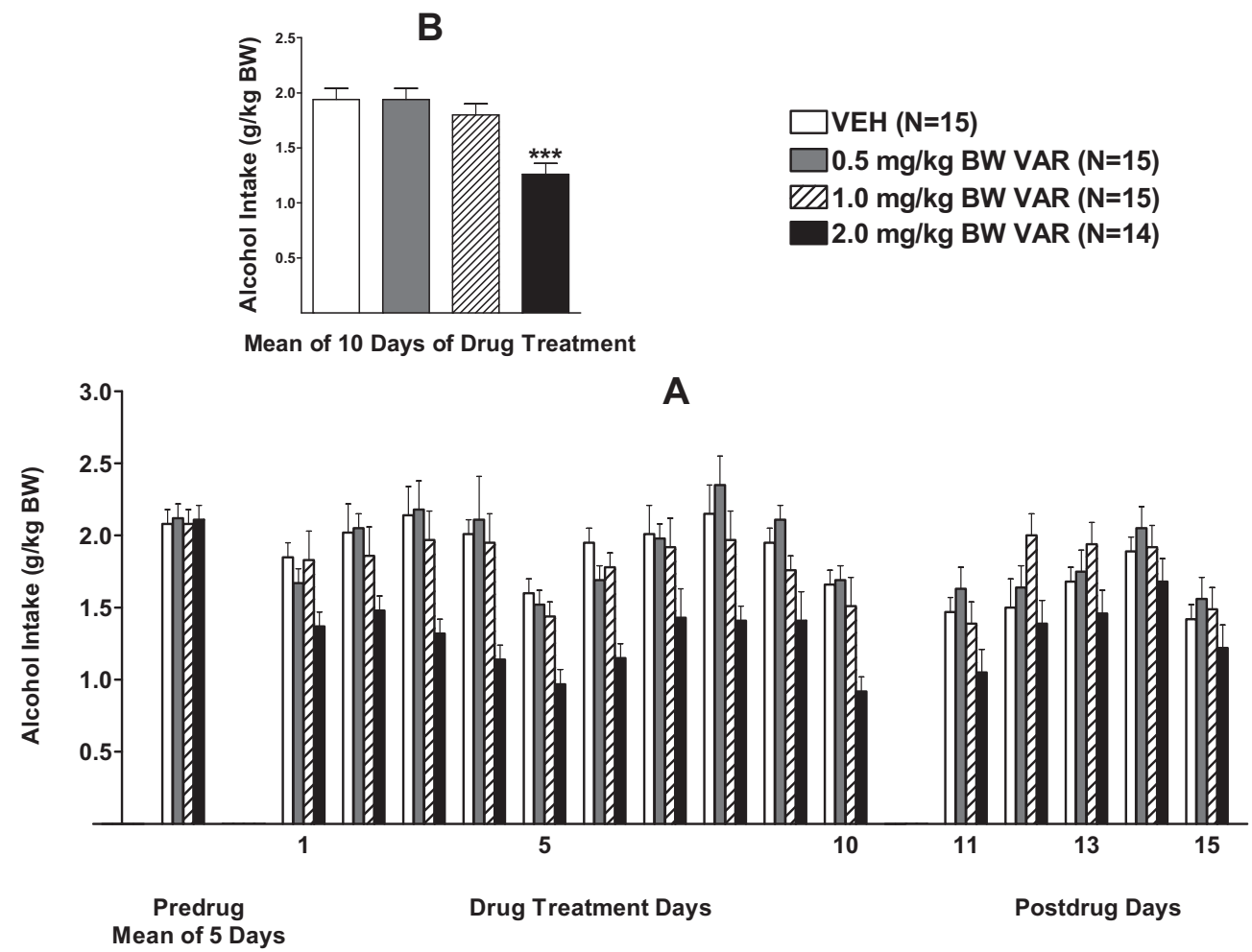

Fig. 2. (A) Effect of oral varenicline (VAR) $(0.5,1.0$, or $2.0 \mathrm{mg} / \mathrm{kg}$ body weight [BW]) or vehicle (VEH), given 1 hour prior to alcohol access, on alcohol intake in male $P$ rats given access to alcohol $(15 \% \mathrm{v} / \mathrm{v})$ for 2 hours a day. (B) Effect of VAR or VEH on mean alcohol intake over the 10 days of drug treatment. $* * * p<0.001$ versus VEH. Each point represents the mean \pm SE.
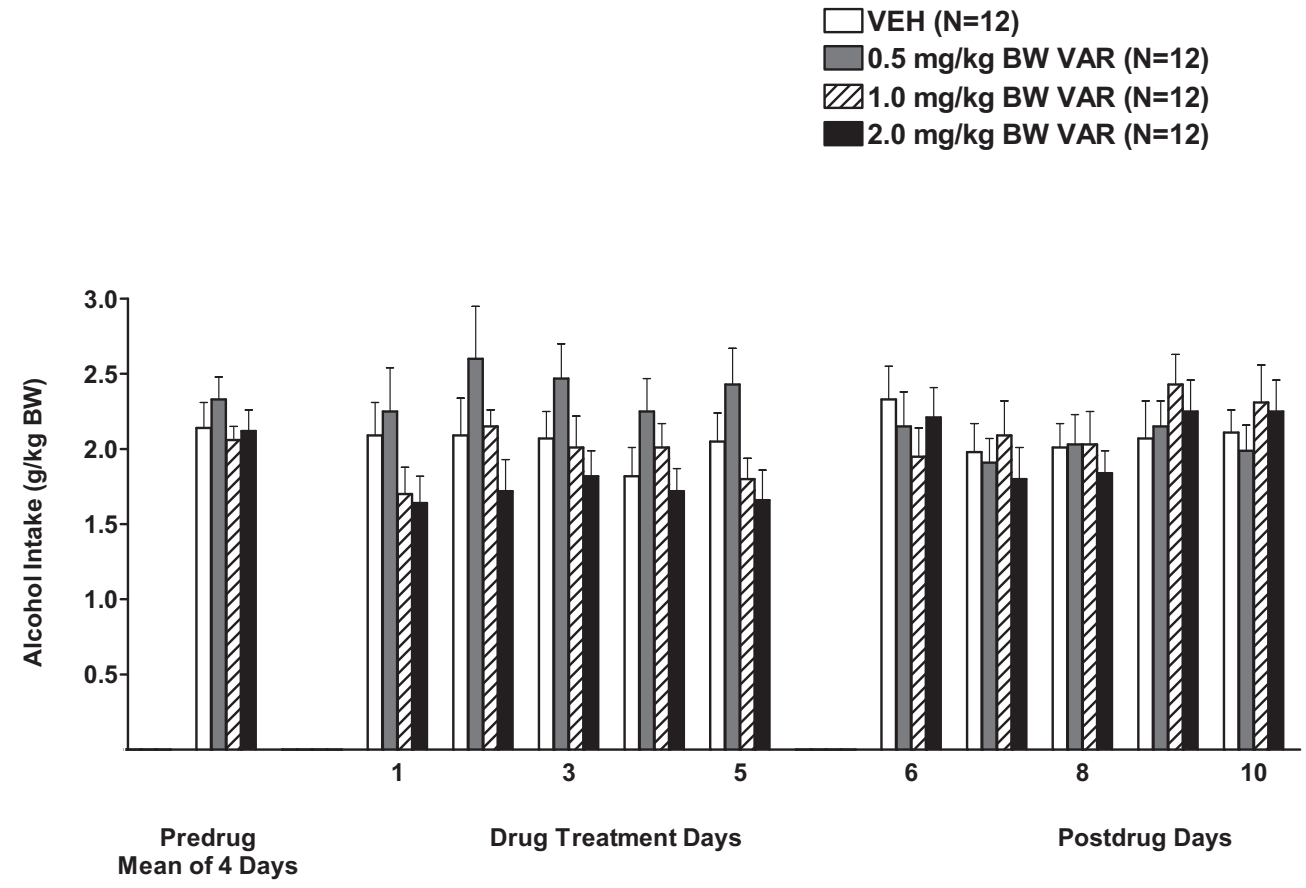

Fig. 3. Effect of oral varenicline (VAR) $(0,0.5,1.0$, or $2.0 \mathrm{mg} / \mathrm{kg}$ body weight [BW]) or vehicle (VEH), given 2 hours prior to alcohol access, on alcohol intake in male $\mathrm{P}$ rats given access to alcohol $(15 \% \mathrm{v} / \mathrm{v})$ for 2 hours a day. Each point represents the mean $\pm \mathrm{SE}$.

\section{Effect of NTX Alone on Alcohol Intake}

Alcohol intake during the 2 weeks of NTX treatment $(5 \mathrm{~d} /$ wk) was analyzed using a 2-way RM ANOVA (dose $\times$ day, RM on day). The results revealed that there was a significant effect of treatment, $F(3,55)=7.04$, $p<0.001$, a significant effect of day, $F(9,495)=5.87$, 
$p<0.001$, but no significant interaction ( $p=0.32$; Fig. $4 A$ ). Dunnett's multiple comparisons against a single mean revealed that only the $20.0 \mathrm{mg}$ dose of NTX significantly reduced $(p<0.001)$ alcohol intake when compared with VEH (Fig. 4B).

One-way ANOVAs were conducted, one for each day, to analyze how long the treatment effect of $20.0 \mathrm{mg} \mathrm{NTX} / \mathrm{kg}$ BW lasted. The ANOVAs revealed that 20.0 NTX reduced alcohol intake on all 10 days of drug treatment when compared to VEH $(p<0.05, p<0.01$, or $p<0.001$ depending on the day; Fig. 4A).

With regard to alcohol intake following termination of treatment, there was no effect of dose $(p=0.17)$, a significant effect of day, $F(4,220)=7.80, p<0.001$, and no interaction $(p=0.82)$.

\section{Effect of VAR + NTX on Alcohol Intake}

Alcohol intake during the first week of combination drug treatment (days 1 to 5) was analyzed with a 2-way RM ANOVA (treatment $x$ day with RM on day). There were significant effects of treatment, $F(4,54)=15.27$, $p<0.001$, and day, $F(4,216)=3.98, p<0.01$, but no significant interaction $(p=0.32)$. Dunnett's multiple comparison against a single mean revealed that alcohol intake in all 4 combination drug treatment groups was significantly lower than intake in the VEH-treated group $(p<0.001$; Fig. 5B).

Alcohol intake during the entire 3 weeks of combination drug treatment $(5 \mathrm{~d} / \mathrm{wk})$ was analyzed with a 2-way $\mathrm{RM}$
ANOVA (dose $x$ day, with RM on day). There were significant effects of treatment, $F(4,54)=8.07, p<0.001$, and day $F(14,756)=15.84, p<0.001$, and a significant treatment $\times$ day interaction, $F(56,756)=1.83, \quad p<0.001$ (Fig. 5A). Fisher's LSD test revealed that alcohol intake in all dose combination groups was significantly lower than alcohol intake in the VEH-treated group $(0.5 \mathrm{VAR}+10.0$ NTX $[p=0.055], 0.5$ VAR +15.0 NTX $[p<0.05], 1.0$ $\mathrm{VAR}+10.0$ NTX $[p<0.001], 1.0 \quad \mathrm{VAR}+15.0$ NTX $[p<0.001]$; Fig. $5 C$ ). Fisher's LSD test also revealed that alcohol intake in the highest VAR dose groups (1.0 VAR + 10.0 NTX and 1.0 VAR + 15.0 NTX) was significantly lower than intake in the 0.5 VAR dose groups $(p<0.01$ and $p<0.01$, respectively) regardless of the NTX dose that VAR was combined with. Further pairwise comparisons with Fisher's LSD revealed that, when compared to VEH, 1.0 VAR + 15.0 NTX reduced alcohol intake on 14 of the 15 treatment days $(p<0.05, p<0.01$, or $p<0.001$, depending on the day), 1.0 VAR + 10.0 NTX reduced alcohol on 11 of the 15 treatment days $(p<0.05, p<0.01$, or $p<0.001$, depending on the day), 0.5 VAR + 15.0 NTX reduced alcohol intake on 6 of the 15 treatment days ( $p<0.05, p<0.01$, or $p<0.001$, depending on the day), and 0.5 VAR + 10.0 NTX reduced alcohol intake on only 5 of the 15 treatment days $(p<0.05, p<0.01$, or $p<0.001$, depending on the day).

With regard to alcohol intake after termination of VAR + NTX treatment (Fig. $5 A$ ), there was no effect of treatment $(p=0.68)$, or day $(p=0.17)$, and no interaction $(p=0.94)$.

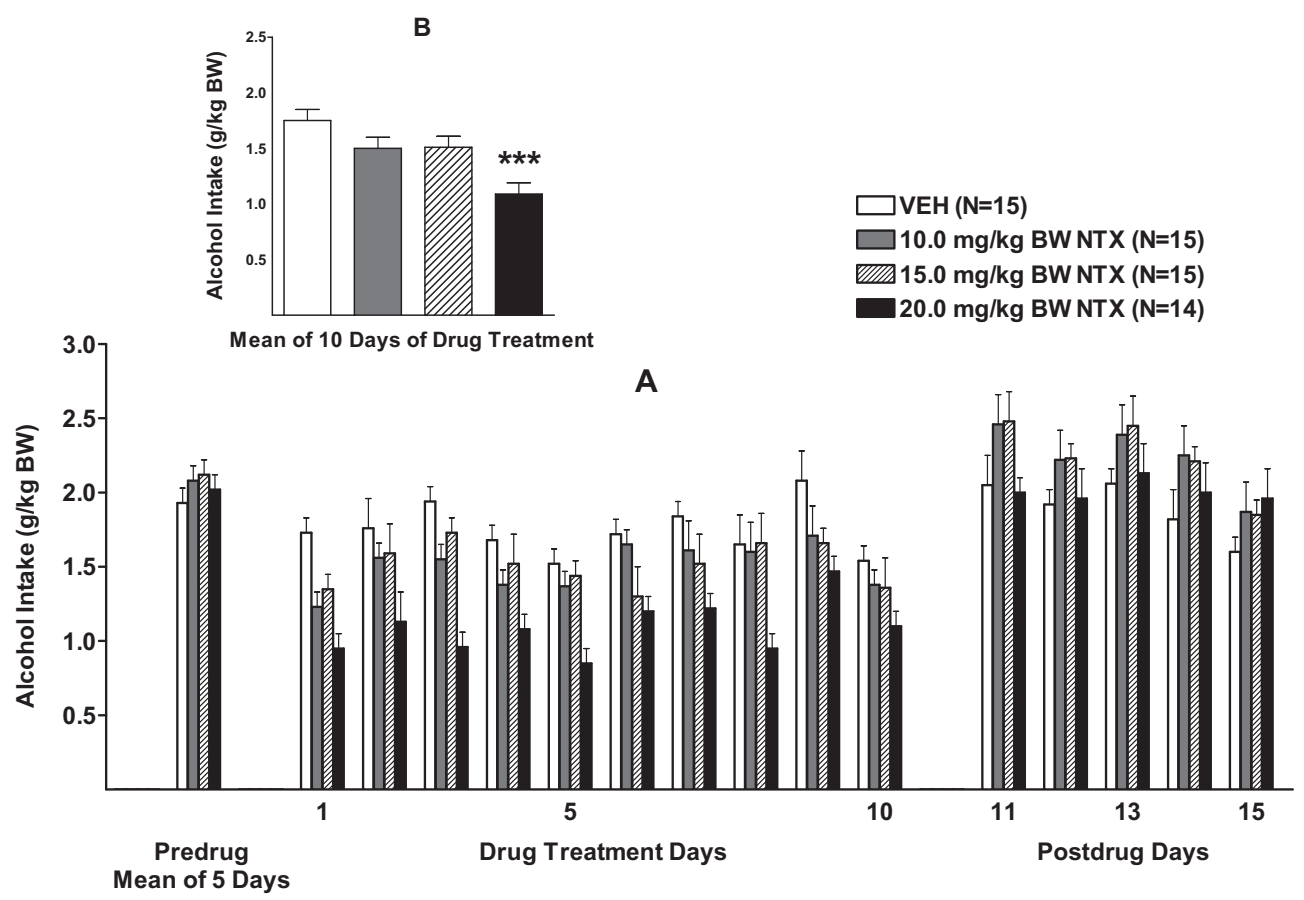

Fig. 4. (A) Effect of oral naltrexone (NTX) (10.0, 15.0, or $20.0 \mathrm{mg} / \mathrm{kg}$ body weight [BW]) or vehicle (VEH) on alcohol intake in male $\mathrm{P}$ rats given access to alcohol $(15 \% \mathrm{v} / \mathrm{v})$ for 2 hours a day. (B) Effect of NTX or VEH on mean alcohol intake over the 10 days of drug treatment. $* * * p<0.001$ versus VEH. Each point represents the mean \pm SE. 


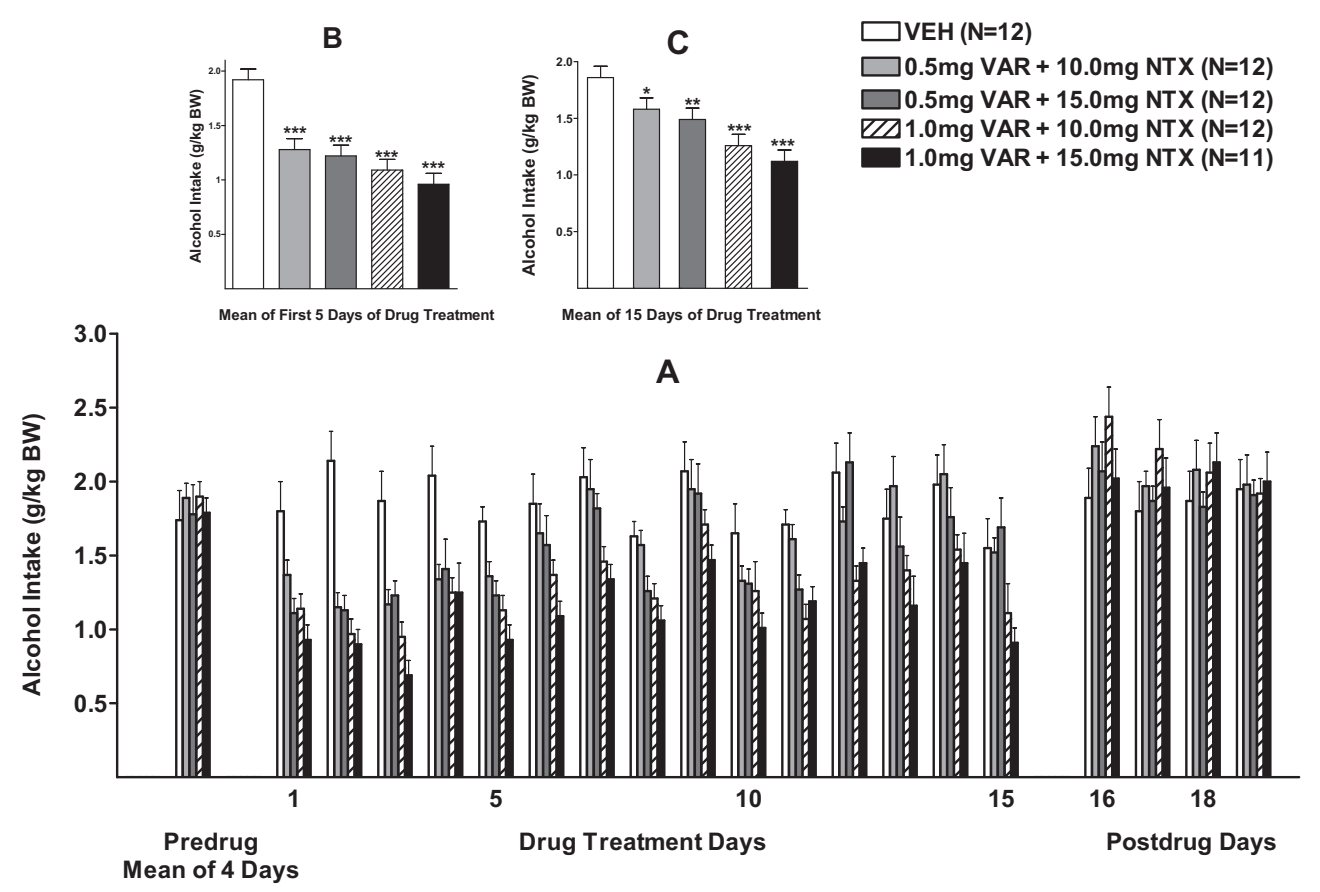

Fig. 5. (A) Effect of oral varenicline + naltrexone (VAR + NTX) $(0.5+10.0,0.5+15.0,1.0+10.0$, or $1.0+15.0 \mathrm{mg} / \mathrm{kg}$ body weight [BW]) or vehicle (VEH) on alcohol intake in male P rats given access to alcohol $(15 \% \mathrm{~V} / \mathrm{v})$ for 2 hours a day. (B) Effect of VAR + NTX VEH on mean alcohol intake over the first 5 days of drug treatment. (C) Effect of VAR + NTX or VEH on mean alcohol intake over the full 15 days of drug treatment. $* p<0.05, * * p<0.01$, $* * * p<0.001$ versus VEH. Each point represents the mean \pm SE.

\section{Effect of VAR + NTX on BAC}

With regard to the effect of 5 days of treatment (VAR $1.0 \mathrm{mg} / \mathrm{kg} \mathrm{BW}+\mathrm{NTX} 10.0 \mathrm{mg} / \mathrm{kg} \mathrm{BW}$ ) on BAC, a 2-way RM ANOVA (treatment $\times$ time with RM on time) revealed no significant effect of treatment $(p=0.74)$, a significant effect of time $(p<0.001)$, and no significant interaction $(p=0.69)$. The peak BAC was 150 to $170 \mathrm{mg} \%$ at 30 to 90 minutes after IG infusion with $2.0 \mathrm{~g}$ alcohol $/ \mathrm{kg} \mathrm{BW}$ in

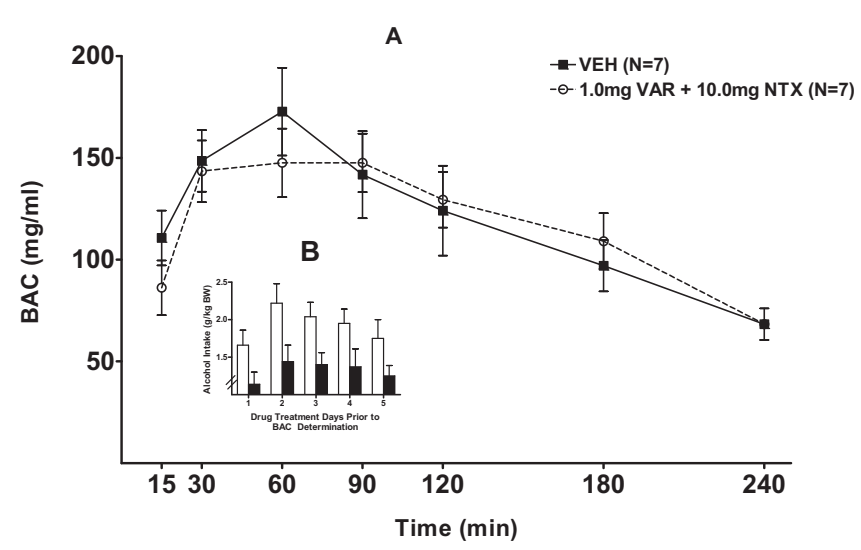

Fig. 6. (A) Effect of oral varenicline + naltrexone (VAR + NTX) $(1.0 \mathrm{mg}+10.0 \mathrm{mg})$ or vehicle $(\mathrm{VEH})$ on blood alcohol concentration (BAC) following an intragastric infusion of alcohol $(2.0 \mathrm{~g} / \mathrm{kg} \mathrm{BW})$ in $P$ rats. (B) Effect of VAR + NTX $(1.0+10.0 \mathrm{mg} / \mathrm{kg}$ body weight [BW] $)$ or VEH on alcohol intake in the $P$ rats depicted in (A) during the 5 days of drug treatment preceding BAC determination. Each point represents the mean $\pm \mathrm{SE}$. both the group pretreated with VEH and in the group pretreated with $1.0 \mathrm{mg} / \mathrm{kg} \mathrm{VAR}+10.0 \mathrm{mg} / \mathrm{kg}$ NTX (Fig. $6 A$ ).

With regard to the alcohol intake during the 5 days of treatment (VAR $1.0 \mathrm{mg} / \mathrm{kg} \mathrm{BW}+$ NTX $10.0 \mathrm{mg} / \mathrm{kg} \mathrm{BW}$ ) prior to BAC determination, there was a significant effect of dose, $F(1,16)=7.38, p<0.05$, no effect of day $(p=0.08)$, and no interaction $(p=0.92)$. Dunnett's post hoc analysis revealed that the treatment of 1.0 VAR + 15.0 NTX reduced alcohol intake when compared to VEH (Fig. 6B).

\section{DISCUSSION}

Given the global prevalence of alcohol addiction, it is critical that people seeking help have access to effective treatments including medications as well as psychosocial interventions. Currently, there are only 3 FDA approved drugs for the treatment of alcohol addiction: disulfiram (antabuse) which was approved in 1949, NTX (Trexan or Revia) which was approved in 1994, and acamprosate (campral) which was approved in 2004. None of these drugs are effective for all alcoholics and none are without side effects. Clearly, additional medications are needed to assist alcoholics and heavy drinkers in reducing their alcohol intake when they seek treatment on a voluntary basis as well as when treatment for alcohol abuse is delivered in closed care facilities.

Our research group has had a long-standing interest in identifying medications that have the potential to reduce alcohol abuse and alcoholism safely and effectively. NTX 
has been extensively characterized in both rodents and humans (for review, see Froehlich et al., 2003; O'Malley and Froehlich, 2003) and is the most effective medication available for decreasing alcohol intake (Maisel et al., 2013). However, NTX is underutilized because its efficacy is modest, it is not without side effects, it is not effective for all alcoholics, and, when it is effective, a number of alcoholics fail to maintain initial treatment gains and relapse to heavy drinking. We have recently begun to investigate the potential value of combining NTX with other medications in order to allow efficacy to be achieved at lower doses thus avoiding potential side effects. For instance, we have found that prazosin, a drug used to treat post traumatic stress disorder, decreases alcohol drinking in a rodent model of alcoholism when administered alone (Froehlich et al., 2013a, 2015; Rasmussen et al., 2009) and combining low-dose NTX with lowdose prazosin, in a single medication, decreases alcohol drinking more effectively than does either drug alone (Froehlich et al., 2013b).

The current study focused on VAR, a relatively new drug that has been well characterized with regard to its effect on nicotine intake. VAR is marketed for, and used to, decrease cigarette smoking but a few studies have reported that it also decreases alcohol intake (Bito-Onon et al., 2011; Chatterjee et al., 2011; Ericson et al., 2009). For instance, a recent study of cigarette smokers, who also drank alcohol heavily, reported that while VAR decreased smoking, as expected, a combination of VAR and NTX also reduced alcohol drinking and, when compared to placebo, reduced the "high" produced by alcohol (Ray et al., 2014). This may be due, in part, to the fact that NTX and VAR share a common mechanism of action with regard to the dopaminergic system. Alcohol stimulates the release of endogenous opioids (for review, see Froehlich and Li, 1993, 1994) which in turn results in an increase in DA release in the nucleus accumbens (Di Chiara and Imperato, 1988; Imperato and Di Chiara, 1986; Weiss et al., 1993). This increase in DA release mediates the euphoria that accompanies alcohol drinking and that serves to reinforce subsequent alcohol drinking (Samson et al., 1992). NTX blocks opioid receptors which results in decreased alcohol-induced DA release in the nucleus accumbens (Benjamin et al., 1993; Dudek et al., 2016) thus reducing alcoholinduced euphoria and the reinforcing properties of alcohol. VAR also decreases DA release in the nucleus accumbens by binding to the $\alpha 4 \beta 2$ nicotinic receptors (Hendrickson et al., 2013; Rollema et al., 2007). Hence, both NTX and VAR reduce alcohol-induced euphoria and alcohol reinforcement through inhibition of alcohol-induced DA release.

Based on our prior work with drug combinations (Froehlich et al., 2013b; Rasmussen et al., 2014, 2015), we predicted that combining an ineffective dose of NTX with an ineffective dose of VAR in a single medication would decrease alcohol intake more effectively than would either drug alone. The results of the current study support this prediction. During week 1 of treatment, low doses of VAR $(0.5$ and $1.0 \mathrm{mg} / \mathrm{kg}$ $\mathrm{BW})$ and low doses of NTX (10.0 and $15.0 \mathrm{mg} / \mathrm{kg} \mathrm{BW})$, when given alone, were not effective in decreasing alcohol drinking. However, when ineffective doses of the 2 drugs were combined, alcohol intake was significantly reduced when compared to $\mathrm{VEH}$, and the effect was seen in all lowdose combinations tested. Of particular importance is the fact that the reduction in alcohol drinking occurred immediately after onset of treatment with the combined medication and continued throughout 3 weeks of treatment. The low-dose combination decreased alcohol intake as effectively as did higher doses of VAR $(2.0 \mathrm{mg} / \mathrm{kg} \mathrm{BW})$ or NTX $(20.0 \mathrm{mg} / \mathrm{kg} \mathrm{BW})$ alone. The reduction in alcohol intake seen following VAR + NTX treatment was not due to drug-induced changes in alcohol absorption or clearance as evidenced by a similar magnitude and time course of the BAC following an IG infusion of alcohol in rats previously treated for 5 days with the drug combination (1.0 VAR + 10.0 NTX) or with VEH. The drug combination decreased alcohol intake on all 5 days of treatment but did not alter BAC in response to an IG infusion of alcohol.

The ability of VAR alone, NTX alone, and VAR + NTX to decrease alcohol intake disappeared after termination of drug treatment. However, there was a strong trend toward a significant effect of high-dose VAR in reducing alcohol intake on the day following termination of treatment which suggests that the duration of action of VAR may surpass that of NTX.

The doses of NTX used in the current study (10.0 to $20.0 \mathrm{mg} / \mathrm{kg}$ BW) are higher than those used via nonoral routes. This is because NTX has a low bioavailability when administered orally (Hussain et al., 1987). Consequently, a larger dose is required to produce a comparable serum level of NTX to that seen when lower doses are given via nonoral routes. In rats, NTX has an oral bioavailability of $1 \%$, which is lower than the 15 to $25 \%$ bioavailability found in humans (Goodman and Gilman, 2011). This low oral potency of NTX in rats is due to a rapid first pass metabolism, rather than to gastro intestinal factors (Shepard et al., 1985). In contrast, VAR is well absorbed after oral administration and has a bioavailability of $>87 \%$ (Goodman and Gilman, 2011; Obach et al., 2005). Therefore, a given dose of VAR is equally effective if given via nonoral or oral routes (McKee et al., 2009; Steensland et al., 2007). We are not aware of any interactions between NTX and VAR that would alter side effects associated with the combination in rodents or humans.

When administered orally in rodents (via gavage), the $t_{1 / 2}$ of VAR is $4.0 \pm 0.9$ hours (Obach et al., 2005). In the current study, we compared the effect of 2 lead times, 1 and 2 hours, between oral administration of VAR and onset of access to alcohol. We found that VAR $(2.0 \mathrm{mg} / \mathrm{kg} \mathrm{BW})$ was effective in reducing alcohol intake when given 1 hour prior to onset of alcohol access, but was not effective when given 2 hours prior to alcohol. The 1-hour lead time appears optimal for VAR-induced reductions in alcohol drinking when administered orally in rodents.

It should be noted that neither VAR nor NTX, alone or in combination, eliminated alcohol drinking in $\mathrm{P}$ rats. While 
elimination of drinking (complete abstinence), can be achieved by humans, this usually occurs when psychosocial approaches are combined with medication in individuals with a high motivation to stop drinking. Rats lack the psychosocial elements (counseling, network support, social pressure) that contribute significantly to abstinence in humans, and hence, an elimination of alcohol drinking would not be expected in the current study in which rats received medication alone. The fact that VAR + NTX, in a combined medication, reduced alcohol drinking without the contribution of psychosocial elements suggests that these drugs may be particularly effective for alcoholics and heavy drinkers who are motivated to reduce their drinking through the use of medications together with psychosocial interventions as part of a comprehensive treatment program for alcohol use disorders.

Using lower doses of drugs in combination has 2 potential benefits. First, use of low doses may eliminate adverse side effects. This is important with regard to NTX, which can produce occasional malaise, depression-like symptoms, and dysphoria (Hollister et al., 1981; Malcolm et al., 1987; Oncken et al., 2001) and with regard to VAR which can produce sleep disorders, increased fatigue, and jaundice in the case of drug-induced liver injury (Mogensen and Bjornsson, 2015; Thomas et al., 2015). In the current study, a low dose of VAR + NTX was as effective in decreasing alcohol intake as was a high dose of either drug alone even during the first week of drug treatment. The fact that low-dose VAR + NTX was effective in the first week of treatment, when the probability of relapse in alcoholics is high, is important because inpatients are typically instructed to abstain from alcohol for several days before starting a drug treatment, during which time alcohol craving escalates (personal conversation, Dr. Tim Kelley, Medical Director, Fairbanks Alcohol and Drug Treatment Center, 2012). A fast acting medication may help prevent relapse in these patients. For those in the outpatient setting, increased effectiveness of a combined medication in the first week of treatment is likely to promote a positive long-term outcome because an immediate positive effect may reinforce the decision to continue voluntary treatment (Christensen, 1978).

There is an urgent need for new approaches to treat alcoholism and alcohol abuse. A single medication may not be optimal for all stages of alcohol abuse or for different types of alcohol use disorders. A "personalized medicine" or "precision medicine" approach would allow for tailoring of drug combinations to meet the needs of individual patients. The results of the current study suggest that a combination of low-dose VAR + NTX may be effective when used early in the treatment process by alcoholics and heavy drinkers who do not respond well to a single medication.

\section{ACKNOWLEDGMENTS}

We thank Dr. Ting-Kai Li and the Indiana Alcohol Research Center for supplying the selectively bred rats used in this study and Pfizer International for providing the varenicline. This work was supported by NIH grants R01 AA021208 (JCF) and P60 AA007611 (JCF). There are no conflict of interests in this manuscript.

\section{REFERENCES}

Anton RF, O'Malley SS, Ciraulo DA, Cisler RA, Couper D, Donovan DM, Gastfriend DR, Hosking JD, Johnson BA, LoCastro JS, Longabaugh R, Mason BJ, Mattson ME, Miller WR, Pettinati HM, Randall CL, Swift R, Weiss RD, Williams LD, Zweben A (2006) Combined pharmacotherapies and behavioral interventions for alcohol dependence. The COMBINE study: a randomized controlled trial. JAMA 295:2003-2017.

Benjamin D, Grant ER, Pohorecky LA (1993) Naltrexone reverses ethanolinduced dopamine release in the nucleus accumbens in awake, freely moving rats. Brain Res 621:137-140.

Bernard A, Delattre A, Lamelin P (1964) The mechanism of action of alcohol on the gastric mucosa: its hygroscopic and dehydrating properties. Acta Gastroenterol Belg 27:129-147.

Bito-Onon JJ, Simms JA, Chatterjee S, Holgate J, Bartlett SE (2011) Varenicline, a partial agonist at neuronal nicotinic acetylcholine receptors, reduces nicotine-induced increases in $20 \%$ ethanol operant self-administration in Sprague-Dawley rats. Addict Biol 16:440-449.

Bull LS, Pitts GC (1971) Gastric capacity and energy absorption in the forcefed rat. J Nutr 101:593-596.

Chatterjee S, Steensland P, Simms JA, Holgate J, Coe JW, Hurst RS, Shaffer CL, Lowe J, Rollema H, Bartlett SE (2011) Partial agonists of the $\alpha 3 \beta 4 *$ neuronal nicotinic acetylcholine receptor reduce ethanol consumption and seeking in rats. Neuropsychopharmacology 36:603-615.

Christensen DB (1978) Drug-taking compliance: a review and synthesis. Health Serv Res 13:171-187.

Di Chiara G, Imperato A (1988) Drugs abused by humans preferentially increase synaptic dopamine concentrations in the mesolimbic system of freely moving rats. Proc Natl Acad Sci USA 85:5274-5278.

Dudek M, Canals S, Sommer WH, Hyytiä P (2016) Modulation of nucleus accumbens connectivity by alcohol drinking and naltrexone in alcohol-preferring rats: a manganese-enhanced magnetic resonance imaging study. Eur Neuropsychopharmacol 26:445-455.

Ericson M, Löf E, Stomberg R, Söderpalm B (2009) The smoking cessation mediation varenicline attenuates alcohol and nicotine interactions in the rat mesolimbic dopamine system. J Pharmacol Exp Ther 329: 225-230.

Faessel HM, Smith BJ, Gibbs MA, Gobey JS, Clark DJ, Burstein AH (2006) Single-dose pharmacokinetics of varenicline, a selective nicotinic receptor partial agonist, in healthy smokers and nonsmokers. J Clin Pharmacol 46:991-998.

Forsander OA, Sinclair JD (1992) Alcohol elimination and regulation of alcohol consumption in AA and ANA rats. Alcohol Alcohol 27:411-416.

Froehlich JC, Harts J, Lumeng L, Li T-K (1990) Naloxone attenuates voluntary ethanol intake in rats selectively bred for high ethanol preference. Pharmacol Biochem Behav 35:385-390.

Froehlich JC, Hausauer BJ, Federoff DL, Fischer SM, Rasmussen DD (2013a) Prazosin reduces alcohol drinking throughout prolonged treatment and blocks the initiation of drinking in rats selectively bred for high alcohol intake. Alcohol Clin Exp Res 37:1552-1560.

Froehlich JC, Hausauer BJ, Fischer SM, Wise B, Rasmussen DD (2015) Prazosin reduces alcohol intake in an animal model of alcohol relapse. Alcohol Clin Exp Res 39:1538-1546.

Froehlich JC, Hausauer BJ, Rasmussen DD (2013b) Combining naltrexone and prazosin in a single oral medication decreases alcohol drinking more effectively than does either drug alone. Alcohol Clin Exp Res 37:1763-1770.

Froehlich JC, Li T-K (1991) Animal models of the study of alcoholism: utility of selected lines. J Addict Dis 10:61-71.

Froehlich JC, Li T-K (1993) Opioid peptides, in Recent Developments in Alcoholism, Vol. 11: Ten Years of Progess (Glanter M ed), pp 187-205. Plenum Publishing Co., New York, NY. 
Froehlich JC, Li T-K (1994) Opioid involvement. Ann N Y Acad Sci 739:156-167.

Froehlich JC, O'Malley S, Hyytia P, Davidson D, Farren C (2003) Preclinical and clinical studies on naltrexone: what have they taught each other? Alcohol Clin Exp Res 27:533-539.

Froehlich JC, Zweifel M, Harts J, Lumeng L, Li T-K (1991) Importance of delta opioid receptors in maintaining alcohol drinking. Psychopharmacology 103:467-472.

Fucito LM, Toll BA, Wu R, Romano DM, Tek E, O'Malley SS (2011) A preliminary investigation of varenicline for heavy drinking smokers. Psychopharmacology 215:655-663.

Fuller RK, Branchey L, Brightwell DR, Derman RM, Emrick CD, Iber FL, James KE, Lacoursiere RB, Lee KK, Lowenstam I, Maany I, Neiderhiser D, Nocks JJ, Shaw S (1986) Disulfiram treatment of alcoholism: a veterans administration cooperative study. JAMA 256:1449-1455.

Gillespie RJ, Lucas CC (1961) Effect of single intoxicating doses of ethanol on the gastric and intestinal mucosa of rats. Can J Biochem Physiol 39:237-241.

Goodman LS, Gilman A (2011) The Pharmacological Basis of Therapeutics, 12th ed. McGraw-Hill, New York, NY.

Hendrickson LM, Guildford MJ, Tapper AR (2013) Neuronal nicotinic acetylcholine receptors: common molecular substrates of nicotine and alcohol dependence. Front Psychiatry 4:29.

Hollister LE, Johnson K, Boukhazba D, Gillespie HK (1981) Aversive effects of naltrexone in subjects not dependent on opiates. Drug Alcohol Depend 8:37-41.

Hussain MA, Aungst BJ, Kearney A, Shefter E (1987) Buccal and oral bioavailability of naloxone and naltrexone in rats. Int J Pharm 36:127-130.

Imperato A, Di Chiara G (1986) Preferential stimulation of dopamine release in the nucleus accumbens of freely moving rats by ethanol. J Pharmacol Exp Ther 239:219-228.

Koob GF (1992) Neural mechanisms of drug reinforcement. Ann N Y Acad Sci 654:171-191.

Kranzler HR, Modesto-Lowe V, Van Kirk J (2000) Naltrexone vs. nefazodone for treatment of alcohol dependence. A placebo-controlled trial. Neuropsychopharmacology 22:493-503.

Krishnan-Sarin S, Krystal JH, Shi J, Pittman B, O’Malley SS (2007) Family history of alcoholism influences naltrexone-induced reduction in alcohol drinking. Biol Psychiatry 62:694-697.

Krystal JH, Cramer JA, Krol WF, Kirk WF, Rosenheck RA; Veterans Affairs Naltrexone Cooperative Study 425 Group (2001) Naltrexone in the treatment of alcohol dependence. N Engl J Med 345:1734-1739.

Li XW, Li T-K, Froehlich JC (1998) Enhanced sensitivity of the nucleus accumbens proenkephalin system to alcohol in rats selectively bred for alcohol preference. Brain Res 1:35-47.

Linesman MA, Le AD (1997) Effects of opioids on the absorption of alcohol. Pharmacol Biochem Behav 58:79-84.

Maisel NC, Blodgett JC, Blodgett JC, Wilbourne PL, Humphreys K, Finney JW (2013) Meta-analysis of naltrexone and acamprosate for treating alcohol use disorders: when are these medications most helpful? Addiction 108:275-293.

Malcolm R, O'Neil PM, Von JM, Dickerson PC (1987) Naltrexone and dysphoria: a double-blind placebo controlled trial. Biol Psychiatry 22:710-716.

McKee SA, Harrison ELR, O'Malley SS, Krishnan-Sarin S, Shi J, Tetrault JM, Picciotto MR, Petrakis IL, Estevez N, Balchunas E (2009) Varenicline reduces alcohol self-administration in heavy-drinking smokers. Biol Psychiatry $66: 185-190$.

Mogensen H, Bjornsson ES (2015) Varenicline-induced acute liver injury with jaundice. Hepatology 61:2110-2111.

Murphy JM, Gatto GJ, Waller MB, McBride WJ, Lumeng L, Li T-K (1986) Effects of scheduled access on ethanol intake by the alcohol-preferring (P) line of rats. Alcohol 3:331-336.

National Institute on Alcohol and Alcohol Abuse (2008) What is a standard drink? [NIAAA Website]. Available at: http://pubs.niaaa.nih.gov/publica tion/practitioner/pocket\%20guide/pocket-guide2.htm. Accessed March 2, 2016.
Obach RS, Reed-Hagen AE, Krueger SS, Obach BJ, O'Connell TN, Zandi KS, Miller S, Coe JW (2005) Metabolism and disposition of varenicline, a selective $\alpha 4 \beta 2$ acetylcholine receptor partial agonist, in vivo and in vitro. Drug Metab Dispos 34:121-130.

O'Connor EC, Parker D, Rollema H, Mead AN (2009) The alpha4beta2 nicotinic acetylcholine-receptor partial agonist varenicline inhibits both nicotine self-administration following repeated dosing and reinstatement of nicotine seeking in rats. Psychopharmacology 208:365-376.

O'Malley S, Froehlich JC (2003) Advances in the use of naltrexone: an integration of preclinical and clinical findings, in Recent Developments in Alcoholism XVI: Research on Alcoholism Treatment (Galanter M ed), pp 217245. Kluwer Academic/Plenum Publishers, New York, NY.

O'Malley SS, Jaffe AJ, Chang G, Schottenfeld RS, Meyer RE, Rounsaville B (1992) Naltrexone and coping skills therapy for alcohol dependence: a controlled study. Arch Gen Psychiatry 49:881-887.

Oncken C, Van Kirk J, Kranzler HR (2001) Adverse effects of oral naltrexone: analysis of data from two clinical trials. Psychopharmacology 154:397-402.

Parselak A, Billinger MHU, Schafer C, Wehner HD, Bode C, Bode JC (2004) First-pass metabolism of ethanol in human beings: effect of intravenous infusion of fructose. Alcohol 34:121-125.

Rasmussen DD, Alexander LL, Raskind MA, Froehlich JC (2009) The $\alpha 1$ adrenergic receptor antagonist, prazosin, reduces alcohol drinking in alcohol-preferring (P) rats. Alcohol Clin Exp Res 33:264-272.

Rasmussen DD, Beckwith LE, Kincaid CL, Froehlich JC (2014) Combining the $\alpha 1$-adrenergic receptor antagonist, prazosin, with the $\beta$-adrenergic receptor antagonist, propranolol, reduces alcohol drinking more effectively than either drug alone. Alcohol Clin Exp Res 38:1532-1539.

Rasmussen DD, Kincaid CL, Froehlich JC (2015) Prazosin+naltrexone decreases alcohol drinking more effectively than does either drug alone in $\mathrm{P}$ rats with a protracted history of extensive voluntary alcohol drinking, dependence, and multiple withdrawals. Alcohol Clin Exp Res 39:1832-1841.

Ray LA, Chin PF, Miotto K (2010) Naltrexone for the treatment of alcoholism: clinical findings, mechanisms of action, and pharmacogenetics. CNS Neurol Disord Drug Targets 9:13-22.

Ray LA, Courtney KE, Ghahremani DG, Miotto K, Brody A, London ED (2014) Varenicline, low dose naltrexone, and their combination for heavydrinking smokers: human laboratory findings. Psychopharmacology 231:3843-3853.

Rollema H, Chambers L, Coe J, Glowa J, Hurst R, Lebel L, Mansbach RS, Mather RJ, Rovetti CC, Sands SB, Schaeffer E, Schulz DW, Tingley FD 3rd, Williams KE (2007) Pharmacological profile of the $\alpha 4 \beta 2$ nicotinic acetylcholine receptor partial agonist varenicline, an effective smoking cessation aid. Neuropharmacology 52:985-994.

Samson HH, Tolliver GA, Haraguchi M, Hodge CW (1992) Alcohol selfadministration: role of mesolimbic dopamine. Ann N Y Acad Sci 654:242253.

Shepard TA, Reuning RH, Aarons LJ (1985) Estimation of area under the curve for drugs subject to enterohepatic cycling. J Pharmacokinet Biopharm 13:589-608.

Steensland P, Simms JA, Holgate J, Richards JK, Bartlett SE (2007) Varenicline, an $\alpha 4 \beta 2$ nicotinic acetylcholine receptor partial agonist, selectively decreases ethanol consumption and seeking. Proc Natl Acad Sci USA 104:12518-12523.

Thomas KH, Martin RM, Knipe DW, Higgins JPT, Gunnell D (2015) Risk of neuropsychiatric adverse events associated with varenicline: systematic review and meta-analysis. Br Med J 350:h1109.

Volpicelli JR, Alterman AI, Hayashida M, O'Brien CP (1992) Naltrexone and the treatment of alcohol dependence. Arch Gen Psychiatry 49:876-880.

Volpicelli JR, Watson NT, King AC, Sherman CE, O'Brien CP (1995) Effect of naltrexone on alcohol "high" in alcoholics. Am J Psychiatry 152:613615.

Weiss F, Lorang MT, Bloom FE, Koob GF (1993) Oral alcohol self-administration stimulates dopamine release in the rat nucleus accumbens: genetic and motivational determinants. J Pharmacol Exp Ther 267:250-258. 